\title{
PEMBUATAN SOL KARET LEMBARAN UNTUK SANDAL
}

\author{
Herminiwati $^{1)}$ dan Niken Karsiati ${ }^{1)}$
}

\section{INTISARI}

Penelitian ini bertujuan untuk mendapatkan formulasi terbaik dalam pembuatan sol karet lembaran untuk sandal. Formulasi kompon dibuat dengan variasi perbandingan karet alam dan karet sintetis SBR sebagai berikut : 100/0, 75/25, 50/50, 25/25 dan 0/100, sedang variasi perbandingan filler carbon black dan aluminium silikat berturut-turut 100/0, 60/40, dan 20/80. Proses komponding dilakukan dengan alat two roll mill, kompon karet divulkanisasi pada suhu $150^{\circ} \mathrm{C}$, tekanan $150 \mathrm{~kg} / \mathrm{cm}^{2}$ dan waktu vulkanisasi sesuai dengan waktu pada curometer. Vulkanisat karet diuji menurut SNI. 06-0899-1989: Lembaran karet cetak untuk sol. Formulasi terbaik terdiri atas karet alam $75 \mathrm{phr}$, karet sintetik SBR $25 \mathrm{phr}$, asam stearat $3 \mathrm{phr}$, Zn O $5 \mathrm{phr}$, minyak Minarek B 5 phr, carbon black 100 phr, MBTS 1 phr, PBN 1 phr dan sulfur 2 phr. Sifat fisis formulasi terbaik adalah : tegangan putus $185,42 \mathrm{~kg} / \mathrm{cm}^{2}$, perpanjangan putus $276,64 \%$, ketahanan sobek $158,90 \mathrm{~kg} / \mathrm{cm}^{2}$, kekerasan 74 shore A, bobot jenis $1,21 \mathrm{~g} / \mathrm{cm}^{3}$, ketahanan kikis Grasselli $0,326 \mathrm{~mm}^{3} / \mathrm{kgm}$, perpanjangan tetap $7,8 \%$ dan tidak retak pada uji ketahanan retak lentur, serta memenuhi persyaratan SNI. 06-0899-1989.

\section{ABSTRACT}

The purpose of the research was to find the best formulation for rubber sole sheeting for sandal. The formulation of the compounds were made by variation ratio of natural rubber and sintetic rubber SBR as follow : 100/0,75/25,50/50,25/75 and 0/100, where as the variation ratio of carbon black N330 and aluminium silicate filler 100/0, 60/40 and 20/ 80 respectively. Compounding process was carried out on two roll mill.

The rubber compounds were vulcanized at temperature $150^{\circ} \mathrm{C}$ and pressure of 150 $\mathrm{kg} / \mathrm{cm}^{2}$ with curing time as indicated by curometer. Vulcanized rubber were tested based on SNI. 06-0899-1989: Rubber sheeting for sole. The best formulation was consist of natural rubber $75 \mathrm{phr}$, sintetic rubber SBR $25 \mathrm{phr}$, stearic acid $3 \mathrm{phr}$, zinc oxide $5 \mathrm{phr}$, Minarex B oil $5 \mathrm{phr}$, carbon black $100 \mathrm{phr}$, MBTS $1 \mathrm{phr}$, PBN $1 \mathrm{phr}$ and sulfur $2 \mathrm{phr}$. The physical properties of the best compound were : tensile strength $185,42 \mathrm{~kg} / \mathrm{cm}^{2}$, elongation at break $276,64 \%$, tear resistance $158,90 \mathrm{~kg} / \mathrm{cm}^{2}$, hardness 74 shore A, density $1,21 \mathrm{~g} / \mathrm{cm}^{3}$, Grasselli abrasion resistance $0,326 \mathrm{~mm}^{3} / \mathrm{kgm}$, permanent set $7,78 \%$ and no crack on the flex cracking test. The best compound could meet the requirements of SNI. 06-0899-1989. -

\section{PENDAHULUAN}

Sandal adalah salah satu tipe alas kaki yang masih terus bertahan sampai saat ini dan merupakan salah satu jenis alas kaki yang biasa digunakan di negara-negara yang berhawa panas. Dibeberapa negara sandal bahkan sudah ada sejak beribu tahun sebelum Masehi dengan berbagai model tali maupun ban (band) serta mempunyai ornamen yang indah.

1) Balai Besar Penelitian dan Pengembangan Industri Barang Kulit, Karet dan Plastik Yogyakarta 
Pada prinsipnya sandal terdiri dari sol sebagai alas kaki dengan satu atau beberapa tali (straps) maupun ban (band) yang menutup jari kaki atau menyilang (Anonymous,1976). Berdasarkan definisi tersebut sandal dapat bervariasi mulai sandal dengan sol kayu (sandal kesehatan) sampai sandal wanita dengan sol dan hak serta dekorasi pada ban ataupun talinya. Apabila sandal mempunyai bentuk tali atau ban yang lebar sehingga bagian atas sandal menjadi tertutup, maka disebut sebagai sepatu. Sebaliknya sepatu yang mempunyai banyak lubang/ celah sehingga bagian atas sepatu relatif terbuka maka disebut sandal (Anonymous, 1982).

Sol merupakan bagian yang penting dan menentukan kualitas dari alas kaki tersebut. Sol sandal dapat dibuat dari karet alam, karet sintetikatau campurannya.

Karet alam merupakan polimer dengan unit isopren $-\mathrm{CH}_{2}-\mathrm{C}=\mathrm{CH}-\mathrm{CH}_{2}-$ dan mempunyai berat molekul antara 200.000-400.000. Karet alam terkenal karena kekuatan (strength) dari vulkanisatnya seperti tegangan putus (tensile strength), kekuatan sobek (tear strength) dan ketahanan kikis (abrasion resistance). Disamping itu sifat penting karet alam lainnya adalah elastisitasnya bila rantai molekulnya makin panjang. Molekul panjang pada umumnya tidak lurus, tetapi melingkar seperti spiral dan hal inilah yang menyebabkan karet dapat ditarik dalam batas-batas tertentu. Dalam tiap unit isopren terdapat satu ikatan ganda, dan ikatan tersebut serta gugus $C_{1} \alpha$ metilen merupakan gugus reaktif untuk reaksi vulkanisasi dengan belerang.

Karet sintetik styrene butadiene (SBR) mempunyai berat molekul antara 250.000800.000 dan merupakan polimer yang terdiri dari unit butadiene dan styrene :

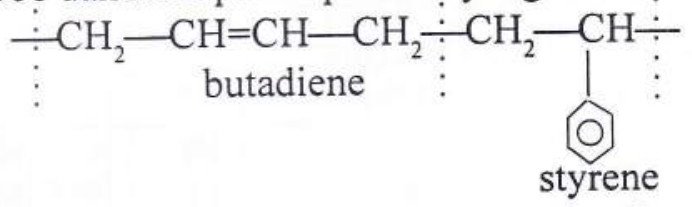

Berbeda dengan karet alam maka gum vulkanisat SBR mempunyai tegangan putus dan ketahanan sobek rendah. Akan tetapi penambahan filler aktif seperti carbon black maupun white filler yang bersifat aktif dapat meningkatkan sifat mekanik setara dengan vulkanisat dari karet alam. Penggunaan filler silikat akan memberikan ketahanan kikis yang tinggi dan meningkatkan ketahanan sobek. Sifat-sifat mekanik vulkanisat SBR dipengaruhi oleh jumlah dan jenis filler. Penambahan carbon black pada pada karet SBR dalam jumlah optimum, memberikan sifat tegangan putus sebesar pada karet alam, namun ketahanan sobeknya masih rendah. Demikian pula elastisitas vulkanisat SBR lebih rendah dibanding karet alam.

Oleh karena itu dalam pembuatan sol karet lembaran untuk sandal perlu kiranya diteliti pengaruh penggunaan karet alam, karet sintetik dan campurannya serta penambahan filler carbon black dan aluminium silikat guna mendapatkan formulasi terbaik.

\section{BAHAN DAN METODA PENELITIAN}

\section{Bahan Penelitian}

Bahan penelitian terdiri atas karet alam (RSS I), karet sintetik Styrene Butadiene Rubber (SBR), filler carbon black N330 dan aluminium silikat, minyak Minarek B, asam stearat, zink oksida, benzothiazyl disulfide (MBTS), phenyl $\beta$ napthylamine (PBN) dan sulfur. Bahan penelitian diperoleh dari PT. Marhas Bandung. 


\section{Peralatan Penelitian}

Alat penelitian terdiri atas two roll mill, hidrolik pres, neraca, alat uji tensile strength, durometer A, alat uji kikis Grasselli, alat uji permanent set dan alat uji Ross flexing.

\section{Metoda Penelitian}

1. Formulasi kompon

Dalam penelitian ini akan dilihat pengaruh kombinasi bahan baku karet alam dan karet sintetik SBR dengan kombinasi filler carbon black dan aluminium silikat. Formula kompon adalah sebagai berikut :

$\begin{array}{ll}\text { Karet alam (RSS I) } & : 100,75,50,25,0 \mathrm{phr} \\ \text { Karet sintetik SBR } & : 0,25,50,75,100 \mathrm{phr} \\ \text { Asam stearat } & : 3 \mathrm{phr} \\ \text { Zn O } & : 5 \mathrm{phr} \\ \text { Minarek B } & : 5 \mathrm{phr} \\ \text { Carbon black N330 } & : 100,60,20 \mathrm{phr} \\ \text { Aluminium silikat } & : 0,40,80 \mathrm{phr} \\ \text { MBTS } & : 1 \mathrm{phr} \\ \text { PBN } & : 1 \mathrm{phr} \\ \text { Sulfur } & : 2 \mathrm{phr}\end{array}$

Matriks variasi formulasi penelitian seperti pada Tabel 1

Tabel 1. Matriks variasi formulasi kompon karet untuk sol sandal

\begin{tabular}{|c|c|c|c|c|c|}
\hline \multirow{2}{*}{$\begin{array}{c}\text { Carbon black/Aluminium } \\
\text { Silikat (phr) }\end{array}$} & \multicolumn{6}{|c|}{ Karet alam/karet sintetik (phr) } \\
\cline { 2 - 6 } & $100 / 0$ & $75 / 25$ & $50 / 50$ & $25 / 75$ & $0 / 100$ \\
\hline $100 / 0$ & 1 & 4 & 7 & 10 & 13 \\
$60 / 40$ & 2 & 5 & 8 & 11 & 14 \\
$20 / 80$ & 3 & 6 & 9 & 12 & 15 \\
\hline
\end{tabular}

Keterangan $: \mathrm{phr}=$ per hundred rubber

Berdasarkan matriks di atas diperoleh 15 variasi formulasi yang terdiri dari lima variasi kombinasi karet alam dan karet sintetik serta tiga variasi kombinasi carbon black dan $\mathrm{Al}$. Silikat.

\section{Pembuatan kompon dan vulkanisasi}

Pembuatan kompon dilakukan dengan alat two roll mill. Bahan baku karet lebih dulu dimastikasi sampai plastis. Selanjutnya ditambahkan asam stearat dan digiling sampai homogen, demikian pula akselerator MBTS dan aktivator Zn O. Kemudian berturutturut dimasukkan carbon black, aluminium silikat, Minarek B sambil terus digiling sampai homogen. Antioksidan PBN ditambahkan, kemudian belerang dimasukkan dan digiling lagi sampai homogen.

Sebelum divulkanisasi kompon disimpan pada ruang kondisi dengan suhu $\left(27 \pm 2^{\circ} \mathrm{C}\right)$ dan kelembaban relatif $(65 \pm 5 \%)$ selama minimal 24 jam. Untuk menentukan waktu vulkanisasi optimum, kompon diuji pada alat curometer sedangkan vulkanisasi dilakukan pada suhu $150^{\circ} \mathrm{C}$ dan tekanan $150 \mathrm{~kg} / \mathrm{cm}^{2}$. 


\section{Pengujian}

Vulkanisat karet diuji sesuai dengan SNI. 06-0899-1989 Lembaran Karet Cetak untuk Sol. Parameter yang diamati meliputi tegangan putus, perpanjangan putus, ketahanan sobek, kekerasan, bobot jenis, ketahanan kikis Grasselli, perpanjangan tetap dan ketahanan retak lentur. Hasil uji vulkanisat karet dari berbagai formulasi kemudian dianalisis secara statistik dan dibandingkan dengan persyaratan SNI.

\section{HASIL DAN PEMBAHASAN}

\section{Hasil Penelitian}

Hasil penelitian seperti tertera pada Tabel 2 .

Tabel 2. Hasil Uji vulkanisat sol karet lembaran untuk sandal

\begin{tabular}{|c|c|c|c|c|c|c|c|c|c|}
\hline $\begin{array}{l}\mathrm{CB} / \mathrm{Al} \\
100 / 0\end{array}$ & NR/SR & $\begin{array}{c}\text { Tegangan } \\
\text { putus } \\
\left(\mathrm{kg} / \mathrm{cm}^{2}\right)\end{array}$ & \begin{tabular}{|c|} 
Perpanj- \\
jangan \\
putus (\%)
\end{tabular} & 87,00 & 51,26 & $\begin{array}{c}\begin{array}{c}\text { Bobot } \\
\text { jenis } \\
\left(\mathrm{g} / \mathrm{cm}^{3}\right)\end{array} \\
1,234\end{array}$ & \begin{tabular}{|c|}
$\begin{array}{c}\text { Perpan- } \\
\text { jangan } \\
\text { tetap (\%) }\end{array}$ \\
5,57 \\
\end{tabular} & \begin{tabular}{|c|}
$\begin{array}{c}\text { Ketahanan } \\
\text { kikis graseli } \\
\left(\mathrm{mm}^{2} / \mathrm{kgm}\right)\end{array}$ \\
0,281
\end{tabular} & $\begin{array}{l}\text { Ketahanan } \\
\text { retak lentur } \\
(150 \mathrm{kcs})\end{array}$ \\
\hline $\begin{array}{l}100 / 0 \\
60 / 40\end{array}$ & $100 / 0$ & $\begin{array}{l}134,67 \\
140,26\end{array}$ & $\begin{array}{l}184,78 \\
271,39\end{array}$ & 84,00 & 75,30 & 1,263 & 7,85 & 0,701 & retak \\
\hline $60 / 40$ & $100 / 0$ & $\begin{array}{l}140,26 \\
108,49\end{array}$ & $\begin{array}{l}271,39 \\
402,63\end{array}$ & 76,00 & 102,67 & 1,266 & 9,04 & 2,214 & retak \\
\hline $20 / 80$ & $100 / 0$ & $\begin{array}{l}108,49 \\
185,42\end{array}$ & 276,64 & 74,00 & 158,90 & 1,211 & 7,78 & 0,326 & tidak retak \\
\hline $100 / 0$ & $75 / 25$ & $\begin{array}{l}185,42 \\
142,45\end{array}$ & 267,46 & 87,00 & 80,96 & 1,266 & 5,65 & 0,318 & retak \\
\hline $60 / 40$ & $75 / 25$ & $\begin{array}{l}142,45 \\
107,81\end{array}$ & 352,76 & 83,00 & 76,00 & 1,236 & 8,31 & 1,076 & retak \\
\hline $20 / 80$ & $75 / 25$ & $\begin{array}{l}107,81 \\
151,38\end{array}$ & 172,97 & 90,67 & 66,17 & 1,259 & 4,23 & 0,290 & retak \\
\hline $100 / 0$ & $50 / 50$ & $\begin{array}{l}151,38 \\
124,18\end{array}$ & 217,59 & 89,00 & 70,17 & 1,281 & 9,86 & 0,909 & tidak retak \\
\hline $60 / 40$ & $50 / 50$ & $\begin{array}{l}124,18 \\
110,68\end{array}$ & 300,26 & 85,00 & 74,36 & 1,303 & 8,33 & 0,813 & tidak retak \\
\hline $20 / 80$ & $50 / 50$ & $\begin{array}{l}110,68 \\
146,61\end{array}$ & 149,35 & 93,33 & 82,29 & 1,263 & 11,52 & 0,232 & retak \\
\hline $100 / 0$ & $25 / 75$ & $\begin{array}{l}146,61 \\
125,54\end{array}$ & 214,96 & 87,33 & 76,44 & 1,290 & 9,34 & 0,559 & tidak retak \\
\hline $60 / 40$ & $25 / 75$ & $\begin{array}{l}125,54 \\
107,85\end{array}$ & 339,64 & 84,00 & 72,85 & 1,305 & 8,20 & 0,699 & tidak retak \\
\hline $20 / 80$ & $25 / 75$ & $\begin{array}{l}107,85 \\
195,58\end{array}$ & 184,78 & 93,66 & 83,64 & 1,290 & 8,34 & 0,643 & tidak retak \\
\hline $100 / 0$ & $0 / 100$ & $\begin{array}{l}195,58 \\
152,14\end{array}$ & 254,33 & 86,00 & 88,44 & 1,315 & 8,70 & 0,252 & tidak retak \\
\hline $60 / 40$ & $0 / 100$ & $\begin{array}{l}152,14 \\
129,22\end{array}$ & 418,37 & 82,66 & 77,95 & 1,342 & 7,46 & 0,297 & tidak retak \\
\hline $20 / 80$ & $0 / 100$ & $\frac{129,22}{\text { min. }}$ & & & & maks. & maks. & maks. & \\
\hline \multicolumn{2}{|c|}{$\begin{array}{l}\text { SNI.06- } \\
\text { 0899-1989 }\end{array}$} & $\begin{array}{l}\text { min. } \\
50,00\end{array}$ & $\begin{array}{l}\text { min. } \\
100\end{array}$ & $65-80$ & 30,0 & 1,5 & 10 & 1,5 & tidak retak \\
\hline
\end{tabular}

Keterangan : $\mathrm{CB}=$ Carbon black $\mathrm{Al}=$ Aluminium silikat $\mathrm{BR}=$ Natural rubber $\mathrm{SR}=$ Sintetic rubber

\section{Pembahasan}

\section{penggunaan bahan karet dan filler terhadap tegangan putus dan} perpanjangan putus

Berdasar hasil analisa data menunjukkan bahwa penambahan filler carbon black meningkatkan tegangan putus. Untuk formulasi dengan penggunaan karet SBR sebanyak $100 \mathrm{phr}$ dan filler carbon black $100 \mathrm{phr}$ diperoleh nilai tegangan putus tertinggi dan berbeda nyata $(\mathrm{p} \leq 0,05)$ dibanding formulasi lainnya. Carbon black $\mathrm{N} 330$ adalah filler penguat (reinforcing filler) maka penambahannya dalam kompon karet memberikan nilai tegangan putus yang baik dan memenuhi persyaratan SNI. 06-0899-1989 : Lembaran karet cetak untuk sol, sebaliknya perpanjangan putus makin turun. Menurut SNI persyaratan tegangan putus ditetapkan sebesar minimum $50 \mathrm{~kg} / \mathrm{cm}^{2}$ dan perpanjangan putus sebesar $100 \%$. Penggunaan karet alam, karet sintetik SBR dan kombinasinya disertai penambahan filler penguat memberikan sifat kekuatan yang baik. Dari semua formulasi yang diteliti mempunyai nilai yang dapat memenuhi persyaratan SNI.06-0899- 
1989. Karet alam maupun karet sintetik SBR mempunyai ikatan ganda yang mudah bereaksi dengan gugus aktif yang terdapat pada filler penguat. Carbon black mempuyai gugus fungsional pada permukaan karbon seperti phenolic, hydroxyl, quinone, carboxyl, lactone dan hidrogen reaktif yang mudah berikatan dengan molekul karet, sedangkan aluminium silikat terutama mempunyai gugus hydroxyl.

Terbentuknya ikatan-ikatan diantara molekul karet dengan filler mengakibatkan vulkanisat menjadi kaku dan kuat sehingga apabila ditarik memerlukan beban yang besar. Sebaliknya perpanjangan putus atau elastisitas turun karena rantai polimer karet menjadi kurang bebas bergerak.

\section{Pengaruh penggunaan bahan karet dan filler terhadap ketahanan sobek}

Hasil uji terhadap ketahanan sobek menunjukkan bahwa penambahan filler carbon black $\mathrm{N}$ 330 maupun aluminium silikat dalam kompon karet memberikan nilai ketahanan sobek yang baik dan memenuhi persyaratan SNI. 06-0899-1989. Persyaratan untuk ketahanan sobek menurut SNI ditetapkan sebesar $50 \mathrm{~kg} / \mathrm{cm}^{2}$, maka berdasar persyaratan tersebut semua formulasi yang diteliti mempunyai nilai yang relatif lebih tinggi. Hal tersebut disebabkan karena baik carbon black maupun aluminium silikat adalah filler penguat, sehingga interaksinya dengan molekul karet terjadi baik secara fisika maupun kimia. Interaksi secara fisika terjadi karena adanya daya adsorpsi yang berupa gaya van der Waal's, sedangkan secara kimia terjadi karena terbentuknya ikatan antara gugus fungsional pada permukaan filler dengan molekul karet terutama pada gugus $\mathrm{C} 1 \leq$ metilen. Berdasar analisa data ternyata carbon black bersifat lebih aktif dan cenderung memberikan nilai ketahanan sobek lebih baik dan berbeda nyata $(\mathrm{P} \leq$ $0,05)$ dibanding aluminium silikat. Sifat aktif carbon black yang lebih baik disebabkan karena banyaknya gugus-gugus fungsional pada permukaan carbon.

\section{Pengaruh penggunaan bahan karet dan filler terhadap kekerasan}

Kekerasan dapat dipengaruhi oleh jenis dan jumlah filler maupun bahan baku karet yang digunakan dalam pembuatan kompon. Dari hasil analisa data menunjukkan bahwa makin besar proporsi carbon black dan karet sintetik SBR, kekerasan vulkanisat karet makin tinggi. Formulasi dengan penggunaan karet sintetik SBR 100 phr dan carbon black 100 phr memberikan nilai kekerasan yang tinggi yakni sebesar 93,66 Shore A.

Carbon black adalah filler penguat yang mudah membentuk ikatan dengan karet karena mempunyai gugus-gugus aktif. Oleh karena itu penambahannya dalam kompon akan menaikkan viskositas dan terbentuknya ikatan-ikatan yang mengakibatkan vulkanisat menjadi kaku, kuat dan keras. Dibanding karet alam yang disusun dari unit monomer isoprene, maka karet sintetik SBR yang terdiri dari unit monomer butadiene dan styrene lebih jenuh sehingga bersifat lebih keras.

Ditinjau dari kekerasan, umumnya formulasi yang diteliti mempunyai nilai kekerasan yang lebih tinggi dibanding persyaratan SNI. 06-0899-1989 yang menetapkan persyaratan kekerasan sebesar 65-80 Shore A. Sol sandal utamanya dimaksudkan sebagai pelindung telapak kaki sehingga sering kali diperlukan sol yang keras. Oleh karena itu dalam formulasi kompon yang dibuat diteliti penambahan filler sampai dengan $100 \mathrm{phr}$.

\section{Pengaruh penggunaan bahan karet dan filler terhadap bobot jenis}

Hasil analisa statistik terhadap bobot jenis menunjukkan bahwa jenis karet maupun filler 
mempengaruhi bobot jenis. Makin besar proporsi karet alam maupun carbon black yang ditambahkan dalam kompon karet, bobot jenis makin kecil. Sebaliknya makin besar proporsi SBR dan aluminium silikat, bobot jenis vulkanisat makin tinggi. Vulkanisat dengan penggunaan karet alam $100 \mathrm{phr}$ dan carbon black $100 \mathrm{phr}$ mempunyai bobot jenis $1,234 \mathrm{~g} /$ $\mathrm{cm}^{3}$, sedangkan vulkanisat dengan penggunaan karet sintetik SBR $100 \mathrm{phr}$ dan aluminium silikat $100 \mathrm{phr}$ mempunyai bobot jenis $1,342 \mathrm{~g} / \mathrm{cm}^{3}$ serta menunjukkan beda nyata $(\mathrm{P} \leq$ 0,05). Menurut Mauriya (1981) specific gravity carbon black yakni sebesar 1,75 lebih kecil dibanding specific gravity aluminium silikat sebesar 2,10, sehingga fulkanusat karet dengan filler karbon black bobot jenisnya lebih tinggi dibanding aluminium silikat.

Ditinjau dari persyaratan bobot jenis yang ditetapkan SNI. 06-0899-1989 sebesar maksimum $1,5 \mathrm{~g} / \mathrm{cm}^{3}$ maka semua vulkanisat hasil formulasi yang diteliti dapat memenuhi persyaratan.

\section{Pengaruh penggunaan bahan karet dan filler terhadap ketahanan kikis}

Makin kecil angka ketahanan kikis Grasselli, makin baik karena menunjukkan kemampuan sol karet bertahan terhadap gesekan dengan benda lain. Perhitungan statistik untuk ketahanan kikis menunjukkan bahwa makin besar proporsi carbon black dalam kompon, ketahanan kikisnya makin baik. Demikian juga makin besar proporsi SBR, angka ketahanan kikis makin kecil. Carbon black N 330 atau High abrasion furnace (HAF) adalah filler yang banyak digunakan dalam pembuatan barang karet yang memerlukan ketahanan kikis tinggi diantaranya sol sepatu. Carbon black N 330 adalah filler penguat yang mempunyai ukuran diameter partikel $(31 \mathrm{~nm})$ sehingga mempunyai luas permukaan yang lebih besar dibanding aluminium silikat dengan ukuran diameter partikel $15 \mathrm{~nm}$ (Hofmann, 1989). Oleh karena itu carbon black N 330 dapat terdispersi dengan baik dan merata dalam kompon karet, sehingga interaksi fisika dan kimia dengan molekul karet lebih baik pula. Interaksi secara fisika terjadi karena adanya daya adsorpsi karet dan filler, sedangkan interaksi secara kimia karena terbentuknya ikatan antara gugus fungsional pada permukaan carbon black dengan molekul karet. Carbon black mempunyai efek penguatan yang lebih besar dibanding aluminium silikat. Hasil uji ketahanan kikis dari berbagai formulasi berkisar antara 0,2152$2,2141 \mathrm{~mm}^{3} / \mathrm{kgm}$, berarti semua formulasi yang diteliti dapat memenuhi persyaratan SNI 06-0899-1989 yang mempersyaratkan nilai ketahanan kikis maksimum $2,5 \mathrm{~mm}^{3} / \mathrm{kgm}$.

6. Pengaruh penggunaan bahan karet dan filler terhadap perpanjangan tetap $50 \%$ Perpanjangan tetap 50\% adalah besarnya perubahan panjang dari vulkanisat karet apabila ditarik pada perpanjangan $50 \%$ selama 24 jam. Makin kecil perubahan panjang makin baik, karena deformasi permanen akibat penarikan kecil. Berdasarkan hasil pengujian perpanjangan tetap vulkanisat karet dari berbagai formulasi diperoleh hasil bahwa penggunaan karet alam secara sendiri mempunyai perubahan panjang yang kecil dan berbeda nyata $(\mathrm{P} \leq 0,05)$ dibanding dengan karet SBR secara sendiri maupun kombinasi. Hal tersebut disebabkan karena sifat dasar karet alam yang mempunyai elastisitas sangat baik sehingga apabila ditarik mudah kembali ke bentuk dan panjang semula. Hal tersebut berkaitan dengan struktur polimer karet alam yang panjang melingkar seperti spiral sehingga dapat ditarik dalam batas-batas tertentu. Ditinjau dari jenis filler, maka penggunaan filler aluminium silikat maupun carbon black cenderung memberikan nilai perpanjangan tetap relatif baik. Carbon black dan aluminium silikat merupakan filler aktif sehingga 
penambahannya dalam formulasi kompon meningkatkan jumlah ikatan silang yang terbentuk. Makin banyak ikatan silang yang terbentuk, vulkanisat makin kaku, keras dan elastisitasnya turun sehingga apabila diregangkan dalam waktu lama akan terjadi deformasi permanen.

Persyaratan permanen set menurut SNI. 06-0899-1989, ditetapkan sebesar maksimum $10 \%$ maka berdasarkan persyaratan tersebut, umumnya formulasi yang diteliti dapat memenuhi syarat.

\section{Pengaruh penggunaan bahan karet dan filler terhadap ketahanan retak lentur}

Ketahanan retak lentur merupakan faktor yang penting dalam menentukan kualitas sol. Menurut SNI 06-0899-1989 : Lembaran Karet Cetak untuk Sol, maka persyaratan ketahanan retak lentur adalah tidak boleh retak atau patah pada pembengkukan sebanyak $150.000 \mathrm{kali}(150 \mathrm{kcs})$

Ketahanan retak lentur dapat dipengaruhi oleh jenis dan jumlah bahan pengisi yang digunakan maupun kualitas karet serta bahan-bahan (ingridient) lainnya. Berdasarkan hasil uji ketahanan retak lentur maka belum semua (47\%) formulasi yang diteliti dapat memenuhi persyaratan. Hal tersebut dapat disebabkan karena penambahan filler dalam jumlah yang banyak yakni sebesar $100 \mathrm{phr}$, menyebabkan vulkanisat karet menjadi keras dan kaku serta retak pada pembengkukan 150.000 kali. Selain itu tidak semua filler dapat berikatan dengan molekul karet, sehingga menyebabkan aglomerasi agregat dan terjadinya konsentrasi lokal dari filler. Akibatnya vulkanisat karet menjadi retak apabila dilakukan pembengkukan

\section{KESIMPULAN}

1. Komposisi bahan untuk formula terbaik terdiri atas karet alam (RSS I) $75 \mathrm{phr}$, karet sintetik (SBR) $25 \mathrm{phr}$, asam stearat $3 \mathrm{phr}, \mathrm{ZnO} 5 \mathrm{phr}$, minarek B $5 \mathrm{phr}$, filler carbon black $100 \mathrm{phr}$, MBTS $1 \mathrm{phr}$, PBN $1 \mathrm{phr}$, dan sulfur $2 \mathrm{phr}$.

2. Hasil uji formula terbaik adalah tegangan putus $185,42 \mathrm{~kg} / \mathrm{cm}^{2}$, perpanjangan putus $276,64 \%$, ketahanan sobek $158,90 \mathrm{~kg} / \mathrm{cm}^{2}$, kekerasan 74 shore A, bobot jenis $1,2111 \mathrm{~g} /$ $\mathrm{cm}^{3}$, ketahanan kikis Grasselli $0,326 \mathrm{~mm}^{3} / \mathrm{kgm}$, perpanjangan tetap $7,78 \%$, tidak retak pada uji ketahanan retak lentur $150 \mathrm{kcs}$.

3. Karet alam mempunyai sifat kekuatan yang baik sehingga kombinasinya dengan karet SBR sebanyak $75 \mathrm{phr}$ dibanding $25 \mathrm{phr}$ memberikan sifat fisik yang tinggi. Filler carbon black bersifat lebih aktif dibandingkan Aluminium silikat.

\section{DAFTAR PUSTAKA}

Anonymous, 1976. Footwear Design and Manufacture. Part 1 : Introduction to basic designs, materials, components and constructions Bata Shoe Company Privāte Limited. Main factory, Batanagar, India.

Anonymous, 1982. Product Knowledge. Bata Shoe Organization.

Maurya, G.P., 1981. Rubber Technology and Manufacture. SBP Board of Consultans and Engineers, Small Business Publications, Roop Nagar, Delhi.

Hoffman, W., 1989. Rubber Technology Handbook. Hanser Publisher, Munich Vienna New York.

SNI. 06-0899-1989, Lembaran Karet Cetak untuk Sol. Dewan Standardisasi Nasional. 